\title{
PREVALENCE OF ANTERIOR OPEN BITE AND ITS ETIOLOGICAL FACTORS AMONG A GROUP OF EGYPTIAN CHILDREN: A CROSS SECTIONAL STUDY
}

\author{
Bassant Mohamed El-Mesbahy*, Manal El-Shiekh** and Rasha Mohamed Hatem Hanafy ${ }^{* * *}$
}

\begin{abstract}
Background: Anterior open bite (AOB) is the vertical separation between upper and lower teeth when all other teeth are in maximum intercuspation. It is considered abnormal when it affects patient's function, speech, mastication, future dental health risks and aesthetics.
\end{abstract}

Aim: The current study was conducted to determine the prevalence of anterior open bite and its etiological factors in a group of Egyptian children aged 8 years and above.

Methods: The sample comprised 115 participants aged between 8 and 10 years, attending the Outpatients' Clinic of Pediatric Dentistry and Dental Public Health Department, Faculty of Dentistry, Cairo University. AOB was assessed on study cast models using digital caliper. Increased overjet, abnormal oral habits, and parents' educational level were checked. A close ended questionnaire was answered by patients' guardians. Data were statistically analyzed with SPSS software package (version 21 SPSS Inc., Chicago, USA).

Results: About 24(20.9\%) of the 115 participants had AOB, 82 (71.2\%) had normal overbite, $9(7.8 \%)$ had increased overbite. Overjet relationship was increased in 51(44.4\%). The most common etiological factor was mouth breathing 13(11.3\%). Abnormal oral habits revealed higher percentages of tongue thrust 5 (7.2\%), thumb sucking 4(5.8\%) and lip biting 6(8.7\%) in girls. Boys revealed higher percentages regarding mouth breathing $7(15.2 \%)$ and nail biting $1(2.2 \%)$. There was significant low positive correlation between parents' educational level and the amount of AOB $(\mathrm{r}<0.5$, P-value $<0.05)$.

Conclusions: Prevalence of AOB is relatively low, with no sex predilection. Abnormal oral habit may be a causative factor of $\mathrm{AOB}$.

KEYWORDS: Malocclusion; Mouth breathing; Open bite; Oral habit; Tongue thrust.

* Graduated master degree student, Pediatric Dentistry and Dental public health, Faculty of Dentistry, Cairo University, Egypt

** Associate professor of Pediatric Dentistry and Dental public health, Faculty of Dentistry, Cairo University, Egypt.

*** Lecturer of Pediatric Dentistry and Dental public health, Faculty of Dentistry, Cairo University, Egypt. 


\section{INTRODUCTION}

Dental occlusion has widespread controversies which influence the oral health. Normal occlusion is the relationship between maxillary and mandibular teeth at resting position and during function. Proper evaluation of dental occlusion during childhood has an impact on the need for orthodontic treatment. ${ }^{1}$

Open bite is one of the most prevalent malocclusions and requires the most difficult orthodontic treatment. Early diagnosis and treatment are related to the period of growth and development especially in deciduous and mixed dentition stages. Anterior open bite is considered to be one of the most challenging dentofacial deformities to treat due to the difficulties in determining the causes, formulating a diagnosis and the potential for relapse after treatment. ${ }^{2-3}$

Open bite can be simple without abnormal measures to the vertical cephalometric analysis or complex with disharmony in the skeletal components of the anterior facial height. It is usually associated with Class I, II or III skeletal discrepancies. ${ }^{2}$ Open bites can be classified into dental, which results from the obstruction of the normal eruption of the anterior teeth without compromising the dento alveolar height and skeletal open bites, with manifested craniofacial dysplasia, of similar pattern, but variable severity. ${ }^{4}$

Anterior open bite (AOB) is multifactorial in origin. It has various causes such as: tongue thrusting, non-nutritive sucking, airway obstruction, neurological disturbances, muscular dystrophy, iatrogenic and pathological open bite. ${ }^{4}$

Resting tongue position and tongue position during function define the determination of altered occlusal patterns such as those observed in AOB. ${ }^{5}$

The current study was performed to evaluate the prevalence of $\mathrm{AOB}$ and its etiological factors among a group of Egyptian children in the mixed dentition stage, aged 8 to 10 years.

\section{SUBJECTS AND METHODS}

\section{Study settings}

This study was conducted in the Pediatric Dentistry and Dental Public Health Department, Faculty of Dentistry, Cairo University. Patients were screened during the period from January 2018 to May 2019.

\section{Study design}

The present study is a cross sectional study

\section{Sample size calculation}

According to Khalil et al., ${ }^{6}$ The sample size was equal to 115 participants. Sample size was calculated using a precision of 5 , a design effect set at 1 with $95 \%$ CI.

\section{Participants}

\section{Eligibility criteria}

Children fulfilling the following criteria were included in the study:

\section{Inclusion Criteria:}

1. Age from 8 to 10 years old

2. Both genders

3. Mixed dentition

4. Fully erupted upper central incisors

5. Cooperative patients and compliant parents

6. No current/previous history of orthodontic treatment.

\section{Exclusion criteria:}

1.Unerupted permanent central incisors.

2.Allergy to the impression material.

\section{Procedures}

The research protocol was approved by the Department Research Board. Ethical approval was 
obtained from the Research Ethics Committee, Faculty of Dentistry, Cairo University under the reference code: 21418.

The purpose and the procedures of the study were explained to the children and their parents. A written consent was signed by the parents and a verbal assent was obtained from the children before examination.

Dental examination was conducted while the subject was sitting on the dental chair under the dental unit light source using sterile dental mirrors. Alginate (Cavex CA37, Netherlands) impressions for upper and lower arches were taken, using plastic impression trays (Cesoon, Autoclavable impression trays, China) size 1 or 2 , and then poured on a vibrator into study casts. Wax (Cavex, Netherlands) bite was taken to place the dental casts in maximum intercuspation. The vertical and horizontal relations were measured directly on the dental casts using a Boley gauge digital caliper (Digital 6, Mauser, Winterthur, Switzerland), and read to the nearest tenth of a millimeter. Overbite was considered normal when the inter-incisal distance was larger than $0.5 \mathrm{~mm}$ and smaller than $4 \mathrm{~mm}$. Increased overbite was noted when the inter-incisal distance was larger than $4 \mathrm{~mm}$. The bite was considered open when its measure was negative. When the incisal edges were in contact, edge to edge bite was considered. $^{7}$

Normal overjet value was considered when its measure was positive and smaller than $4 \mathrm{~mm}$. Increased overjet was considered when it was larger than $4 \mathrm{~mm}$. Reverse bite was recorded when its measure was negative, according to Goulart et $a l^{8}$

The patients were asked and checked for the existence of any abnormal habit, as a possible etiological factor of $\mathrm{AOB}$, including: tongue thrust, mouth breathing, thumb sucking, lip biting, and nail biting through a closed ended questionnaire given to patients' guardians and answered by (Yes/No).
Tongue thrust was checked by asking the patient to swallow while the lips were apart. During normal swallowing, tongue tip is placed at the curvature of palate just behind maxillary incisors. Abnormal tongue position was detected when tongue tip is placed at the lower incisors, according to Dean et al ${ }^{9}$.

Mouth breathing was examined by asking the patients to take a deep breath from the nose. Mouth breathers were unable to close their lips or hold water between them and they are aware that they had nasal problems, according to Pacheco et al ${ }^{10}$.

The patient with thumb sucking habit may have extraordinarily cleaned and chapped digit, according to Shetty et al ${ }^{11}$.

The lips and the vermilion border might be chapped, dried or eroded, according to Barberia et $a l^{12}$. Upper lip biting was examined by upper lip biting test. The presence or absence of the habit depended on the ability of the lower incisor to touch mucosa, according to Shah et al ${ }^{13}$.

Nail biting was evaluated as the tissues around the nail were checked for presence of infection or distortion, according to Ghanizadeh ${ }^{14}$.

Parents' level of education and socioeconomic status was recorded.

Patients having AOB and abnormal overjet were referred to the Orthodontic Department, Faculty of Dentistry, Cairo University, for treatment.

\section{Addressing potential sources of bias}

\section{a) Selection bias:}

There was no risk of selection bias as the study included all data of children fulfilling the eligibility criteria.

\section{b) Information bias:}

Information bias was avoided by including only the data of all children fulfilling the eligibility criteria and data were sent to the statistician as labeled data to avoid any bias. 


\section{c) Reporting bias:}

Reporting bias was avoided by reporting all data assessed.

\section{Statistical analysis}

The data was analyzed with SPSS software package (version 21 SPSS Inc., Chicago, USA). Comparison was performed using Chi square test while taking $\mathrm{P}$ values of less than 0.05 as statistically significant.

\section{RESULTS}

Among the 115 examined patients, the prevalence of $\mathrm{AOB}$ was 24 (20.9\%), normal overbite was $82(71.2 \%)$ while $9(7.8 \%)$ of the population had increased overbite, as shown in Table 1.

TABLE (1): Prevalence of anterior open bite, normal overbite and increased overbite in (percentage) in the study population

\begin{tabular}{|c|c|c|c|}
\hline & AOB & $\begin{array}{c}\text { Normal } \\
\text { Overbite }\end{array}$ & $\begin{array}{c}\text { Increased } \\
\text { Overbite }\end{array}$ \\
\hline Total \% & $20.9 \%$ & $71.2 \%$ & $7.8 \%$ \\
\hline
\end{tabular}

There was a slight difference between the amount of AOB, in ( $\mathrm{mm})$, between boys and girls; where it was slight higher in girls than in boys with a ratio of 1.23: 1, as shown in Table 2.

TABLE (2): Mean differences and standard deviation values in $(\mathrm{mm})$ for amount of anterior open bite in boys and girls in the study population

\begin{tabular}{|c|c|c|c|c|c|}
\hline \multirow{2}{*}{} & \multicolumn{4}{|c|}{ Gender } & \multirow{2}{*}{ P-value } \\
\cline { 2 - 5 } & \multicolumn{2}{|c|}{ Girls } & \multicolumn{2}{c|}{ Boys } & \\
\cline { 2 - 4 } & Mean & SD & Mean & SD & \\
\hline AOB (mm) & -2.8 & 2.31 & -2.28 & 0.94 & 0.3124 \\
\hline Ratio & \multicolumn{4}{|c|}{$1.23: 1$} & \\
\hline
\end{tabular}

$P$-value $>0.05$ is considered insignificant.
Increased overjet values in $(\mathrm{mm})$ were divided and distributed as $(4-5),(<6),(<7)$ and $(<9.7) \mathrm{mm}$ as $21(18.3 \%), 18(15.7), 5(4.3 \%)$ and $7(6.1 \%)$ respectively, as shown in Table 3.

TABLE (3) Values in (mm), frequency and percentages $(\%)$ of increased overjet in the study population

\begin{tabular}{|c|c|c|c|}
\hline \multicolumn{2}{|c|}{ Values (mm) } & Frequency & Percentage \\
\hline \multirow{4}{*}{$\begin{array}{c}\text { Increased } \\
\text { Overjet }\end{array}$} & From 4 to 5 & 21 & $18.3 \%$ \\
\cline { 2 - 4 } & $<6$ & 18 & $15.7 \%$ \\
\cline { 2 - 4 } & $<7$ & 5 & $4.3 \%$ \\
\cline { 2 - 4 } & $<9.7$ & 7 & $6.1 \%$ \\
\cline { 2 - 4 } & Total \% & 51 & $44.4 \%$ \\
\hline
\end{tabular}

Among the study population, $10 \quad(8.7 \%)$ exhibited tongue thrust habit, $13(11.3 \%)$ were mouth breathers, $8(7.8 \%)$ were thumb suckers, 6 (5.2\%) of them exhibited lip biting habit while 1 $(0.9 \%)$ of them exhibited nail biting habit as shown in table 4 .

TABLE (4) Frequency and percentages of abnormal oral habit among study population

\begin{tabular}{|l|l|l|l|}
\hline \multicolumn{2}{|c|}{} & Frequency & Percentage \\
\hline \multirow{4}{*}{ Tongue Thrust } & Yes & 10 & $8.7 \%$ \\
\cline { 2 - 4 } & No & 105 & $91.3 \%$ \\
\cline { 2 - 4 } & Total \% & 115 & $100 \%$ \\
\hline \multirow{4}{*}{ Thumb Sucking } & Yes & 13 & $11.3 \%$ \\
\cline { 2 - 4 } & No & 102 & $88.7 \%$ \\
\cline { 2 - 4 } & Total \% & 115 & $100 \%$ \\
\hline & Yes & 8 & $7.8 \%$ \\
\cline { 2 - 4 } & Total \% & 115 & $100 \%$ \\
\hline \multirow{4}{*}{ Lip Biting } & Yes & 6 & $5.2 \%$ \\
\cline { 2 - 4 } & No & 109 & $94.8 \%$ \\
\cline { 2 - 4 } & Total \% & 115 & $100 \%$ \\
\hline \multirow{5}{*}{ Nail Biting } & Yes & 1 & $0.9 \%$ \\
\cline { 2 - 4 } & No & 114 & $99.1 \%$ \\
\cline { 2 - 4 } & Total \% & 115 & $100 \%$ \\
\hline & & &
\end{tabular}


Comparison between boys and girls regarding abnormal oral habits revealed higher percentages of tongue thrust 5 (7.2\%), thumb sucking 4 (5.8\%) and lip biting $6(8.7 \%)$ in girls. On the other hand, boys revealed higher percentages regarding mouth breathing $7(15.2 \%)$ and nail biting 1 (2.2\%), as shown in Table 5.

There was insignificant low negative correlation between parents' educational level and tongue thrust, thumb sucking and lip biting, significant low positive correlation between parents' educational level and mouth breathing, and insignificant low positive correlation between parents' educational level and nail biting, as shown in Table 6 .

There was significant low positive correlation between parent's educational level (High and Low) and amount of AOB $(\mathrm{mm})$ as $(\mathrm{r}<0.5)$ and (P-value $<0.05$ ), as shown in Table 7.

TABLE (5) Frequency, percentages (\%) and comparison between abnormal oral habits in boys and girls

\begin{tabular}{|c|c|c|c|c|c|c|}
\hline & \multicolumn{4}{|c|}{ Gender } & \multirow{3}{*}{ P-value } \\
\hline & & \multicolumn{2}{|c|}{ Girls } & \multicolumn{2}{|c|}{ Boys } & \\
\hline & & Frequency & Percentage & Frequency & Percentage & \\
\hline \multirow{2}{*}{ Tongue Thrust } & No & 64 & $92.8 \%$ & 45 & $97.8 \%$ & \multirow{2}{*}{0.23} \\
\hline & Yes & 5 & $7.2 \%$ & 1 & $2.2 \%$ & \\
\hline \multirow{2}{*}{ Mouth Breathing } & No & 63 & $91.3 \%$ & 39 & $84.8 \%$ & \multirow{2}{*}{0.279} \\
\hline & Yes & 6 & $8.7 \%$ & 7 & $15.2 \%$ & \\
\hline \multirow{2}{*}{ Thumb Sucking } & No & 65 & $94.2 \%$ & 44 & $95.7 \%$ & \multirow{2}{*}{0.732} \\
\hline & Yes & 4 & $5.8 \%$ & 2 & $4.3 \%$ & \\
\hline \multirow{2}{*}{ Lip Biting } & No & 63 & $91.3 \%$ & 46 & $100.0 \%$ & \multirow{2}{*}{0.144} \\
\hline & Yes & 6 & $8.7 \%$ & 0 & $0.0 \%$ & \\
\hline \multirow{2}{*}{ Nail Biting } & No & 69 & $100.0 \%$ & 45 & $97.8 \%$ & \multirow{2}{*}{0.762} \\
\hline & Yes & 0 & $0.0 \%$ & 1 & $2.2 \%$ & \\
\hline
\end{tabular}

$P$-value $>0.05$ is considered insignificant.

TABLE (6) Correlation between amount of anterior open bite in $(\mathrm{mm})$ and parents educational level (high and low)

\begin{tabular}{|c|c|c|}
\hline \multicolumn{2}{|c|}{ Spearman's Correlation } & AOB \\
\hline \multirow{2}{*}{$\begin{array}{c}\text { Parent Education } \\
\text { Level }\end{array}$} & $\mathbf{r}$ & .196 \\
\cline { 2 - 3 } & P-value & .036 \\
\cline { 2 - 3 } & $\mathbf{N}$ & 115 \\
\hline
\end{tabular}

$r<-0.5$ is considered weak negative correlation.

$r<0.5$ is considered weak positive correlation.

$P$-value $<0.05$ is considered significant.

$P$-value $>0.05$ is considered insignificant.
TABLE (7) Correlation between abnormal oral habits and parents educational level

\begin{tabular}{|c|c|c|}
\hline & & Parent Educational Level \\
\hline \multirow{3}{*}{$\begin{array}{l}\text { Tongue } \\
\text { Thrust }\end{array}$} & $\mathbf{r}$ & -.007 \\
\hline & P-value & .943 \\
\hline & $\mathbf{N}$ & 115 \\
\hline \multirow{3}{*}{$\begin{array}{c}\text { Mouth } \\
\text { Breathing }\end{array}$} & $\mathbf{r}$ & .192 \\
\hline & P-value & .040 \\
\hline & $\mathbf{N}$ & 115 \\
\hline \multirow{3}{*}{$\begin{array}{l}\text { Thumb } \\
\text { Sucking }\end{array}$} & $\mathbf{r}$ & -.007 \\
\hline & P-value & .943 \\
\hline & $\mathbf{N}$ & 115 \\
\hline \multirow{3}{*}{ Lip Biting } & $\mathbf{r}$ & -.079 \\
\hline & P-value & .404 \\
\hline & $\mathbf{N}$ & 115 \\
\hline
\end{tabular}




\section{DISCUSSION}

Anterior open bite is one of the most prevalent malocclusion and requires complicated orthodontic treatment.

Early diagnosis and treatment are related to the period of growth and development, especially in deciduous and mixed dentition stages, to achieve better prognosis. Therefore, the current study was performed to evaluate the prevalence of $\mathrm{AOB}$ and its etiological factors among a group of Egyptian children in mixed dentition stage.

The age of the patients ranged from 8 to 10 years with a mean age of $(9 \pm 1)$, to assure full eruption of the permanent central incisors with consequent reliability of the measurements of $\mathrm{AOB}$, as transient or temporary AOB could be due to the lack of full eruption of the permanent central incisors. ${ }^{15}$

Measurements in the current study were done on study cast models stabilized into occlusion; as digital models require time to get familiar with the software programs during measurement which may lead to inter examiner variability, in addition to the high cost and also technique error is likely to occur in the identification of reference points..$^{16}$ This was confirmed by Radeke et al ${ }^{17}$ who stated that there were no significant differences between the digital and manual measurement methods.

The same method for measurement of AOB was applied by Naeem and Asad ${ }^{18}$ on randomly chosen models for patients reporting to the Orthodontic Department of Lahore University, unlike $E l$ Motaleb, ${ }^{19}$ who carried out a study on Egyptian schoolchildren aged 12-18 years and made his measurements directly on the patients' mouth using disposable intra-oral ruler which provides arbitrary and less accurate readings than the digitalized records.

The results of the current study showed that the prevalence of AOB among Egyptian children was $(20.9 \%)$ as shown in Table 1 . This was nearly similar to what was found by Granville-Garcia et al ${ }^{20}$ in Brazil which was (19.8\%), Gomes et al ${ }^{21}$ in Northeastern Brazil which was (21.0\%) and Silvestrini-Biavati et al ${ }^{22}$ in Italy which was (18\%).

In the present study, out of the 115 examined subjects, there was slight difference between girls and boys having AOB with a ratio of (1.23:1), as shown in Table 2 This was less than that stated in the study done by El Motaleb, ${ }^{19}$ who reported a ratio of (5: 3) between girls and boys with AOB. This was complementary with Ovia et al ${ }^{23}$ which reported an insignificant gender association in prevalence and severity of AOB.

The amount of AOB recorded in this study equals $(2.8 \pm 2.31) \mathrm{mm}$ and $(2.28 \pm 0.94) \mathrm{mm}$ in girls and boys respectively, with a minimum of 0.69 $\mathrm{mm}$ and a maximum of $9.25 \mathrm{~mm}$ (only 1 case had AOB $9.25 \mathrm{~mm}$ ). This result was complementary to the findings of El Motaleb, ${ }^{19}$ who showed AOB of $3.9 \pm 2.4 \mathrm{~mm}$ with a minimum of $1 \mathrm{~mm}$ and a maximum of $15 \mathrm{~mm}$.

The increased overjet was $51(44.4 \%)$ divided and distributed as $(4-5),(<6),(<7)$ and $(<9.7) \mathrm{mm}$ and $(18.3 \%),(15.7),(4.3 \%)$ and $(6.1 \%)$ respectively, as shown in Table 3. This was nearly similar to those reported by Ferro et al $^{24}$ in Italy reported (48\%) increased overjet whereas Bourzgui et al ${ }^{25}$ in Morocco, reported overjet of 4-6 mm in (17.2\%) and $>6 \mathrm{~mm}$ in $(10 \%)$.

The present study revealed that 13 (11.3\%) were mouth breathers. Mouth breathing habit was the most common etiological factor among study population. This may be due to low tongue position and weak labial muscle tone. This result agreed with Proffit ${ }^{15}$ and was less than what was reported in a study carried out by Shahri and Rezaie ${ }^{26}$ who found that $(70 \%)$ of the patients had mouth breathing in Zahedan.

Tongue thrust, thumb sucking and lip biting showed higher percentages in girls. On the other hand, boys revealed higher percentages regarding mouth breathing and nail biting. 
There was significant low positive correlation between parents' educational level and amount of AOB. This was complementary to Martins et al ${ }^{27}$ who established correlations between the malocclusion and particular bio-psychosocial variables, and, in accordance with Mendes et al ${ }^{28}$ where the occurrence of $\mathrm{AOB}$ was associated with the presence of deleterious oral habits and was approximately three times more likely to occur with AOB.

\section{CONCLUSIONS}

Based on the previous results; prevalence of AOB is relatively low with no sex predilection, mixed dentition is a critical age that can affect the quality of care later on, and cessation of the cause provides better results and prevents relapse of the condition. Also, practicing abnormal oral habits may be a causative factor of AOB. There is a correlation between gender and the type of the abnormal oral habit.

Although, there is a correlation between parents' educational level and the prevalence of mouth breathing and nail biting habits, no correlation was found between it and the prevalence of tongue thrust, thumb sucking and lip biting habits.

\section{REFERENCES}

1. Tanny L, Huang B, Ye Naung N, Currie G. Non-orthodontic intervention and non-nutritive sucking behaviours. A literature review. Kaohsiung J Med Sci. 34(4): 215-222, 2018.

2. Oliveira J, Dutra A, Pereira C, Ayrton de Toledo O. Etiology and treatment of anterior open bite. J Health Sci Inst. 29(2):92-5, 2011.

3. Hassan DS and Abuaffan AH. Prevalence of Anterior Open Bite among Sample of Sudanese University Students. Enz Eng. 5(1):143, 2016.

4. Arora B, Mahajan M, kaur A, Sekhon H. Anterior Open Bite: Review and Management. IOSR-JDMS. 15(6): 01$06,2016$.

5. Gutiérrez D, Garzón J, Franco J, Botero-Mariaca P. Anterior open bite and its relationship with dental arch dimensions and tongue position during swallowing and phonation in individuals aged 8-16 years: A retrospective case-control study, International Orthodontics, 19(1), 107-116, 2021.

6. Khalil A., Rafla S., Qamar N. Frequency of anterior open bite in Preadolescent Patients Reporting for Orthodontic Treatment. Pak Oral Dental J, 2(1), 2010

7. Ireland AJ, McDonald F. Treatment and Biomechanics. The Angle Orthodontist, Oxford, Great Britain:Oxford, UK Press. 84(4): 693-700, 2003.

8. Goulart Cruz F, Marinho C, Pereira Leite F. Relationship between abnormal horizontal or vertical dental overlap and temporomandibular disorders. Rev. odonto ciênc. 24(3):254-257, 2009.

9. Dean, J. A., Jones, J. E.,Vinson, L. Q. A. W., \& McDonald, R. E. McDonald and Avery's dentistry for the child and adolescent. 10th edition, 2016

10. Pacheco M, Casagrande C, Teixeira L, Finck N, \& Araújo M. Guidelines proposal for clinical recognition of mouth breathing children. Dental Press J. Orthod. 20(4), 39-44, 2015.

11. Shetty RM, Shetty M, Shetty NS, Deoghare A. ThreeAlarm System: Revisited to treat Thumb-sucking Habit. Int J Clin Pediatr Dent. 8(1):82-86, 2015.

12. Barberia E, Lucavechi T, Cardenas D, Maroto M. An atypical lingual lesions resulting from the unhealthy habit of sucking the lower lip: clinical case study. J Clin Pediatr Dent. 30(4):280-282, 2006.

13. Shah PJ, Dubey KP, Yadav JP. Predictive value of upper lip bite test and ratio of height to thyromental distance compared to other multivariate airway assessment tests for difficult laryngoscopy in apparently normal patients. J Anaesthesiol Clin Pharmacol. 29:191-5, 2013.

14. Ghanizadeh A. Nail biting; etiology, consequences and management. Iran J Med Sci. 36(2):73-79, 2011.

15. 15-Proffit W, Fields H. Contemporary orthodontics. Ed 5th St. Louis, Mo.: Elsevier/Mosby, 2013.

16. Jiménez-Gayosso S, Carrillo L, López-González S, Medina-Solís C, Scougall-Vilchis R, Hernández-Martínez C, Colomé-Ruiz G, Escoffié-Ramirez M. Difference between manual and digital measurements of dental arches of orthodontic patients. Dental Press J Orthod. 97:22, 2018 .

17. 17- Radeke J, Von der Wense C, Lapatki BG. Comparison of orthodontic measurements on dental plaster casts and 3D scans. J Orofac Orthop. 75(4):264-74, 2014. 
18. Naeem, S and Asad S. Prevalence of anterior open bite in patients reporting for orthodontic treatment. Pakistan Oral \& Dent J. 29: 41-44, 2009.

19. Abd ElMotaleb M, Al Dakroury A, Sharaby F. Prevalence of Anterior Open Bite Among Egyptian Adolescent Population. Aust. J. Basic \& Appl. Sci. 8(1): 533-537, 2014.

20. Granville-Garcia AF, Ferreira JM, Menezes VA. Prevalence of anterior open bite and overjet preschoolers in the city of Recife (PE, Brazil)]. Cien Saude Colet. Brazil. 15(2): 3265-70, 2010

21. Gomes GB, Vieira-andrade RG, Sousa RV De, Firmino RT. Association between oronasopharyngeal abnormalities and malocclusion in Northeastern Brazilian preschoolers. Dental Press J Orthod. 21(3):39-45, 2016.

22. Silvestrini-Biavati A, Salamone S, Silvestrini-Biavati F, Agostino P, Ugolini A. Anterior open-bite and sucking habits in Italian preschool children. Eur J Paediatr Dent. 17(1):43-6, 2016.

23. Ovia M, Jain R, Sandeep A. Prevalence of anterior open bite malocclusion in south indian population. Palarch's
Journal Of Archaeology Of Egypt/Egyptology. 17(7); 3410-3417, 2020.

24. Ferro R, Besostri A, Olivieri A, Stellini E. Prevalence of occlusal traits and orthodontic treatment need in 14 yearold adolescents in Northeast Italy. Eur J Paediatr Dent. 17(1):36-42, 2016.

25. Bourzgui F, Sebbar M, Hamza M, Lazrak L, Abidine Z, El Quars F. Prevalence of malocclusions and orthodontic treatment need in 8- to 12-year-old schoolchildren in Casablanca, Morocco.Prog Orthod. 13(2):164-72, 2012.

26. Shahri, F and Rezaie M. The Prevalence of Anterior Open Bite in 12-15 Years Old Students in Zahedan. Zahedan. J. Res. Med. Sci. 5(3): 191-195; 2009.

27. Martins-Junior PA, Marques LS, Ramos-Jorge ML. Malocclusion: social, functional and emotional influence on children. J Clin Pediatr Dent. 37(1):103-8, 2012.

28. Mendes S, Ribeiro I, de Castro R, Filgueiras V, Ramos T, Lacerda R. Risk factors for anterior open bite: A casecontrol study. Dent Res J. 17:388-94, 2020. 